\title{
Production of biofuels and biomolecules in the framework of circular economy: A regional case study
}

Waste Management \& Research 2015, Vol. 33(12) 1121-1126 (c) The Author(s) 2015

Reprints and permissions:

sagepub.co.uk/journalsPermissions.nav DOI: 10.1177/0734242X15613154

wmr.sagepub.com

(S)AGE

\section{Nicolas Jacquet, Eric Haubruge and Aurore Richel}

\begin{abstract}
Faced to the economic and energetic context of our society, it is widely recognised that an alternative to fossil fuels and oil-based products will be needed in the nearest future. In this way, development of urban biorefinery could bring many solutions to this problem. Study of the implementation of urban biorefinery highlights two sustainable configurations that provide solutions to the Walloon context by promoting niche markets, developing circular economy and reducing transport of supply feedstock. First, autonomous urban biorefineries are proposed, which use biological waste for the production of added value molecules and/or finished products and are energetically self-sufficient. Second, integrated urban biorefineries, which benefit from an energy supply from a nearby industrial activity. In the Walloon economic context, these types of urban biorefineries could provide solutions by promoting niche markets, developing a circular economy model, optimise the transport of supply feedstock and contribute to the sustainable development.
\end{abstract}

\section{Keywords}

Urban biorefinery, biofuels, bio-based compounds, feedstock, circular economy, waste management

\section{Introduction}

The biorefinery concept can be defined as the sustainable conversion of biomass into a range of marketable bio-based products (platform chemicals, additive molecules for the chemical industry, biomaterials, etc.) and/or bioenergy (biofuels, electricity, heat, etc.) (Laurent et al., 2011). Appearing in the earlier 1980s after the first oil crisis, the development of the biofuels products industry has grown significantly in recent years. The limited availability and gradual increase in the price of oil and petrochemicals, added to the appearance of new environmental concerns (global warming, REACH legislation, etc.), has prompted research institutes and industry to design alternatives to petroleum products (Kamm, 2007).

By proposing biomass as an alternative, biorefineries reduce the current dependence of our society over these fossil resources and allow an efficient use of biomass while minimising waste and global fossil-fuel carbon emissions (Demirbas, 2012; Wiloso et al., 2012).

The current growth of the biorefinery concept also contributes to replacing the concept of 'waste' with 'valuable coproduct(s)'. In recent years, waste management has remained one of the most expensive challenges. To reduce the costs associated to waste management, manufacturers continue to invest to reduce the tonnage. For industry, the idea of a complete recovery of their raw materials (the 'zero waste' paradigm) is linked to a maximum profitability (Jacquet et al., 2015).
In many cases, the 'zero waste' remains inaccessible. However, it could become a reality with the development of specifically designed biorefineries. In this sense, biorefineries in the 'autonomous mode' use residues (solid or liquid waste and coproducts) of their production to generate their own energy. At the opposite end, integrated biorefineries tend to represent the 'ideal' model of the future industry plant. In the framework of industrial ecology, the principle of integrated biorefineries is based on the combination of several companies (production units), where the co-products and the outgoing energy flow of a first unit provides raw material(s) and/or energy to the next. Independently, each of these units is autonomous and market products in a standard way (Kokossis and Yang, 2010). However, the complementarities of all the companies allow achieving the full recovery of raw materials in the most energy-efficient and cost-effective way (circular economy concept).

One factor that ensures the viability of these integrated biorefineries is the proximity of the various production units. Proximity limits the cost associated to the transport of logistics flows between

Gembloux Agro-Bio Tech, University of Liege, Gembloux, Belgium

Corresponding author:

Nicolas Jacquet, Gembloux Agro-Bio Tech, University of Liege,

Passage des Déportés 2, B-5030 Gembloux, Belgium.

Email: nicolas.jacquetaulg.ac.be 
Table 1. Household waste amount theoretically recoverable in the Walloon Region for biorefining applications.

\begin{tabular}{llr}
\hline Method collection & Type of waste & Amount (t) \\
\hline Door-to-door non-selective collection $^{1}$ & Raw domestic waste & 527,393 \\
Door-to-door selective collection $^{1}$ & Green waste & 8688 \\
& Organic waste & 44,822 \\
Municipal waste & Paper and cardboard mixed & 137,125 \\
& Green waste & 19,901 \\
& Organic waste & 617 \\
& Wood & 21,263 \\
Contenair park ${ }^{2}$ & Raw domestic waste (school, & 242 \\
& public administration, etc.) & 107,166 \\
& Paper and cardboard mixed & 167 \\
& Wood & 212,810 \\
& Cardboard & 1844 \\
& Green waste & 337 \\
\hline
\end{tabular}

1 Data based on administration statements about household waste collection.

2Established on inter-municipal container parks data.

companies, and implicates, ideally, that integrated production units must be located on the same geographical site (Kokossis, 2014). This notion of proximity allows for the differentiation of biorefinery into two classes, respectively 'rural biorefineries' and 'urban biorefineries'.

Rural biorefinery is a structure that processes valuable edible crops (first generation biorefinery) or their related 'coproducts' (second generation biorefinery) into refined fractions, located at the centre of a farming community. The biorefinery system starts with the harvesting contract of whole crops (grains and straws and coproducts), which are then stored (including drying if required) and fractionated into valuable products and by-products for sale (Audsley and Annetts, 2003).

In a same way, an urban biorefinery, which is usually a second-generation concept, is located in an urban or sub-urban area and uses fundamental waste streams, such as food waste, unrecyclable papers and lignocellulosic feedstock (second generation) for the production of energy (mostly biofuels) and/or bioproducts (Chintala et al., 2013, 2014; Gavrilescu, 2014).

This article evaluates the viability of these (integrated or autonomous) urban biorefineries near the Walloon urban centres where significant volumes of negative-cost feedstocks are concentrated and collected by specific and powerful waste-sorting.

\section{Regional feedstock availability and composition}

In parallel to economic considerations, it is also important to ensure that negative feedstock material supply will be sufficient to ensure the durability of the process.

Considering a regional case, the identification of flows of negative feedstock mobilised in the Walloon Region is subject to various debates. Most estimations are established on the calculation of a theoretical amount of raw material, based on arable
Walloon lands. These approximated estimations obtain an annual availability of cellulose $\left(1.14 * 10^{6} \mathrm{t}\right)$, hemicelluloses $\left(1.12^{*} 10^{6} \mathrm{t}\right)$ and lignin $\left(0.33 * 10^{6} \mathrm{t}\right)$ from the crop yields in cereals, indigenous crops (residues of the culture of potatoes, sugar beet, chicory inulin) and forage crops.

Estimations for 'wood' and industrial residues are more easily accessible, however, the amounts are clearly overestimated because they do not take into account the existing use of this biomass (mulching, energy sector, etc.) and do not provide a realistic picture of the negative feedstock sustainably and reasonably mobilised. Besides the agricultural, forestry residues and dedicated crops, waste and by-products of our consumption or industrial processing activities could theoretically be exploited in second-generation biorefinery schemes. In Wallonia, it appears that organic household waste alone represents hundreds of thousands tonnes per year, as well as green and gardening waste, cardboard and waste papers (Table 1).

Raw domestic waste still contains various unsorted reusable materials, including a majority (41\%) of organic compostable waste ( $16 \%$ of uneaten food, $21 \%$ of waste food and $4 \%$ of garden waste) and about $12 \%$ of paper and cardboard (packaging, etc.).

These materials, actually buried in sanitary landfilling, partially integrated into recycling channels or incinerated for energy production, contain valuable biological molecules and could be used as raw materials in the development of circular economy patterns.

From a chemical point of view, 'compostable' waste (fruit waste, vegetable and meal wastes, mowing waste, etc.), with a moisture higher than $60 \%$, contain between $6 \%$ and $12 \%$ cellulose, $2 \%$ and $5 \%$ of hemicelluloses and $3 \%$ to $17 \%$ lignin (relative to the wet weight); while wood and the cardboard/paper mixed contains between $6 \%$ and $20 \%$ of residual humidity from $28 \%$ to $90 \%$ of cellulose, $7 \%$ to $15 \%$ of hemicelluloses and $2 \%$ to $23 \%$ of lignin (Stuart and El-Halwagi, 2012). 


\section{Economics of negative-cost feedstock}

Economic considerations for negative-cost feedstock have been clearly detailed by Sheldon-Coulson (2007). Authors showed that the use of raw materials with a negative cost impacted the standard business model of the industry. In standard configuration, the goal of the company is to maximise the volume of marketable product, while minimising the process cost and the volume of feedstock. When a negative feedstock is used, the raw material is considered as a source of revenue and the new economic model is considered to maximise the marketable product and feedstock volume, and minimise the production cost.

To analyse more specifically the impact of the negative-cost feedstock, we can consider the profit equation, which aims to maximise the profitability of a company:

$$
\pi=f(a) \cdot P B-a \cdot P A-v(a)-c
$$

where $\pi$ is the profit, $a$ is the feedstock volume, $f(a)$ is the industry output (which depends on feedstock volume), $P A$ is the feedstock price, $P B$ is the output price, $v(a)$ is the variable cost link to feedstock volume and $c$ is the fix cost not linked to feedstock volume.

To simplify this economic equation, the hypothesis that the production function is linear with $f(a)=y \cdot a$ (where $y$ is the yield or the proportion of feedstock converted in final product) is admitted. In this case, the profit can be calculated by using:

$$
\pi=y \cdot a \cdot P B-a \cdot P A-v(a)-c
$$

In this equation, the hypothesis is also made that non-converted feedstock becomes waste that is deposited without generating any cost. Based on this equation, it is possible to determine the impact of a negative-cost feedstock on the profit, by taking the partial derivate of the function depending on the variables of interest.

In a first place, the partial derivate for $y$, gives a yield of:

$$
\frac{\partial \pi}{\partial y}=P B \cdot a
$$

The form of equation (3) shows that the profit increase (resulting of a yield increase) is independent of the feedstock price $P A$. So, yield betterment will always lead to an increase in profit, whether the feedstock cost is negative or positive. This observation, which could seem trivial, puts a damper on the idea that we should not worry about the performance of a process when feedstock has a negative cost. Special attention should always be given to the efficiency of the process to maximise profit. However, the form of equation (3) also shows that the variation of profit based on yield variation depends on $a$, the feedstock volume. The higher the $a$ value, the higher the gain variation will be owing to an increase of the yield.

To specifically study the impact of the volume feedstock on the profit, the partial derivation of equation (1) with respect to $a$ is proposed in:

$$
\frac{\partial \pi}{\partial a}=P B \cdot y-P A-v^{\prime}(a)
$$

Equation analysis shows that, as $P B . y$ is always $>0$, the expression is always positive only if $P A+v^{\prime}(a)$ is negative. If the raw material is a negative-cost feedstock and $P A$ exceeds in absolute value $v^{\prime}(a)$, feedstock revenues are enough to cover the full conversion and an increase of the scale of the plant will always be profitable. In this case, any yield and any product price are sufficient to ensure the rentability of an increase in scale.

Conversely, if the feedstock price is not so negative to offset the conversion cost, an increase of scale will be profitable only if equation (5) is verified:

$$
y>\frac{P A+v^{\prime}(a)}{P B}
$$

In this case, the output price plays an important role in the determination of the minimum yield required to warrant the profitability of the process (Sheldon-Coulson, 2007).

We can conclude, with respect to these equations system, that economic consideration is more complicated than the standard account, which considers that negative-cost feedstock is a source of revenue. If the price of negative feedstock is quite negative to pay fully of the process plant (including amortising cost), there is no limit to the scale of the plant's profitable operation. Otherwise, price of output product(s) will be determinant to identify the minimum required yield and warrant the profitability of the process.

\section{Conversion processes: Feasibility}

First generation technology is the only way that allows biofuel production in a controlled distribution and approval policy. Three types of biofuels are currently recognised and authorised in Belgium: bioethanol integrated in gasolines; fatty acid methyl esters (FAME) to form biodiesel and finally pure vegetable oil.

Beside the production of first generation biofuels, some companies have turned to the production and marketing of derivative compounds from the first generation bioethanol or glucose, both biodiesel co-products. In Belgium, various branches of first generation bio-based production are identified. For example, polylactic acid (PLA), obtained from corn starch, is a biodegradable polymer intended to replace plastics derived from petrochemicals; succinic acid initially derived from petroleum products can now be synthesized from sugars by fermentation; the use of ethanol as a platform molecule for producing bio-based polymers such as polyvinyl chloride (PVC), polyethylene terephthalate (PET) and polyethylene (PE). Ethylene synthesis by dehydration of ethanol is particularly interesting, because it is the basis for the synthesis of all derivatives in $\mathrm{C} 2$, such as ethylene oxide and ethylene glycol.

The raw materials used in first generation processes are rich in starch and free sugars (including grains) or triglycerides (rape), and are converted into simple process units with reasonable 
production costs. However, competition for these raw materials (part of the food production for non-food application) is imposed to diversify sources of possible supply (Jacquet et al., 2015).

In the additional sources of supply, lignocellulosic plant materials offer good prospects. However, the intrinsic chemical complexity of these materials (mainly composed of cellulose, hemicellulose and lignin) requires additional unit operations (pre-treatment processes) with relatively high costs. In addition, transport of lignocellulosic materials (which contain a lot of water), combined with the low conservation time, timing of cultural practices and non-standardisation of the chemical composition, involve constraints to design cost-effective second-generation production units.

Concerning the second-generation biorefinery, Wallonia seems to suffer from an imbalance between lignocellulosic supply actually mobilised and the increasing demand for biobased products. To reverse this trend, three options are being considered.

- To promote niche markets by targeting small tonnage production of molecules with high added value for local consumption or export.

- To modify the linear economic model (extraction-production-consumption-waste disposal) towards a circular economy model, where all materials used in the design of a (bio-based) product are recovered, recycled and upgraded in energy or materials, and where the end-of-life of the product is considered to promote a maximum reuse of all its components as raw materials.

- To develop production units near the raw materials collection points to minimise transport, and secure the supply chain by regulating the input of materials throughout the year.

Considering these three observations, the second generation biorefinery in the Walloon Region could be defined as the conversion of lignocellulosic materials, available in limited geographical areas, into value-added molecules by a circular approach where all intermediate products and co-products are recovered and reused as raw material for sequential production units.

In this way, two types of urban 'biorefineries', located in an urban or sub-urban area, could be implanted near waste treatment facilities (incinerators, sorting centres) and lignocellulosic residues production (by-product of the activities of the UPA, for example).

- Urban biorefineries with autonomous energy production, which use waste for the production of value-added molecules and/or finished products.

- Urban biorefineries integrated with existing industrial structures, benefiting from the energy of some adjacent processing activities.

These urban biorefineries could be seen as a processing unit for converting a single commodity flow (single input) into various intermediate finished or semi-finished products. In the first case, the management of liquid or gaseous effluents, vinasses and solid residue to a heat generation unit and power to allow a biorefinery function in a quasi-autonomous manner (Figure 1). In the second case, the biorefinery has an external supply of energy that will power the various stages of the process (Figure 2).

The conversion of the raw material is ensured by various operation units, including pre-treatment (separation of the main chemical components constituting the vegetable matrix) followed by one or more conversion steps (physical, chemical and/ or enzymatic ones). The processes used for the conversion of lignocellulosic inflows are preferentially performed at low working temperatures, typically below $300^{\circ} \mathrm{C}$, allowing access to a wide range of semi-finished or finished products (referred as the 'biochemical pathway').

\section{Affordable bioproducts and biofuels}

The products range is wide and depends on the nature of the raw material, but also on the nature and conditions of pretreatment and subsequent conversion. Concerning the biofuels production (mainly bioethanol production), further studies are nowadays conducted to make the second-generation bioethanol cost-competitive compared with the first generation. In this context, research is focused on pretreatment techniques, methods of hydrolysis, fermentation and recovery of vinasse with high lignin concentration, in order to improve the process profitability (Balat, 2011; Carvalheiro et al., 2008; Kumar et al., 2009, Talebnia et al., 2010). However, the second-generation biofuels production processes have not yet reached profitability and remain down compared with the first generation (Eggert and Greaker, 2014; Eisentraut, 2010).

In the case of a valuation of lignocellulosic materials by fermentation, interest comes from the C6 sugars (glucose, galactose and mannose) derived from hydrolysis and readily fermentable (including bioethanol). However, the other sugars of the lignocellulosic material (C5: xylose, arabinose, rhamnose) are less assimilated by traditional strains and have low conversion efficiencies. Research has therefore turned to recombinant strains (bacteria and yeasts) able to co-ferment hexoses and pentoses to ethanol and other bio-based products with high yields (Laurent et al., 2011).

Besides the use of a lignocellulosic biomass to produce ethanol, exploration pathways exist for the production of bio-based compounds (molecules or platforms molecules with high values) from the second generation. Many of these ways are still being explored, but some of them have already been completed. In this sense, the report of the US Department of Energy has identified some platform molecules that can be produced from polysaccharides of this biomass. The following list includes these molecules: succinic acid, fumaric acid, maleic acid, 2,5-furandicarboxylic, 3-hydroxypropionic acid, aspartic acid, glutamic acid, glucaric acid, itaconic and levulinic acids, 3-hydroxybutyrolactone, sorbitol, xylitol and arabinitol (Bozell and Petersen, 2010). 


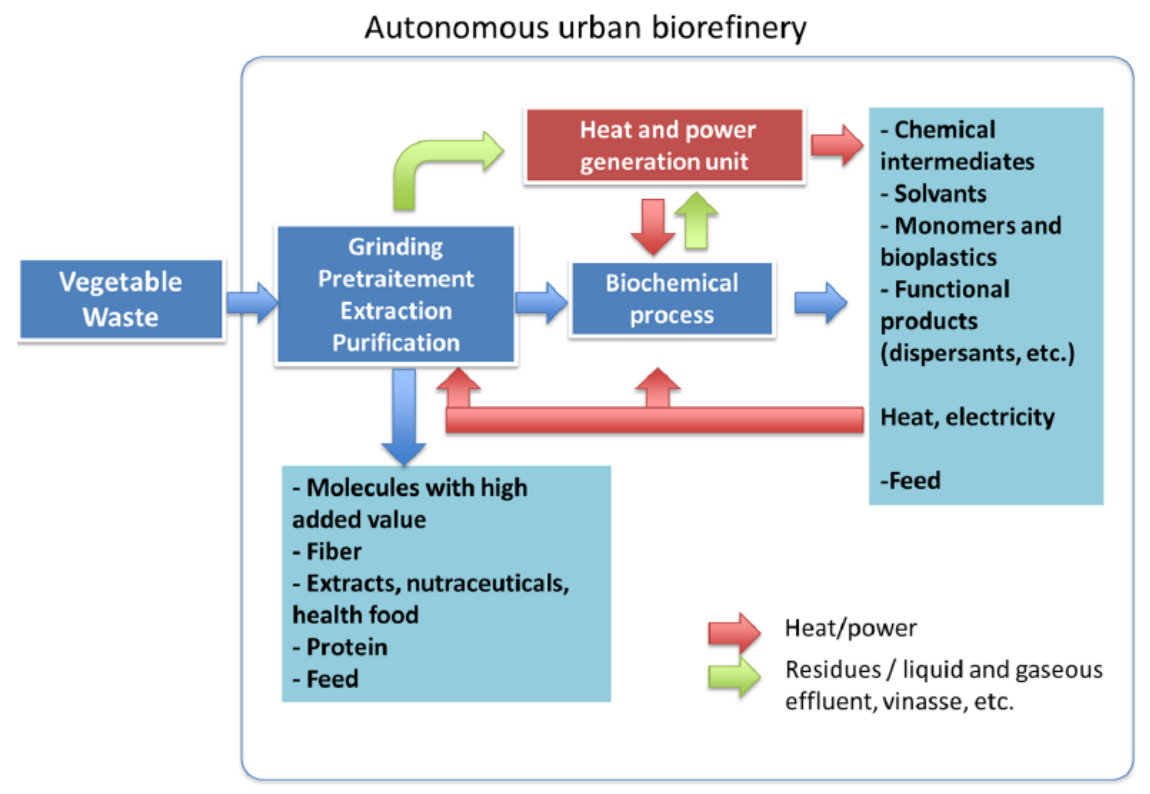

Figure 1. Autonomous urban biorefinery supplied by vegetable waste.

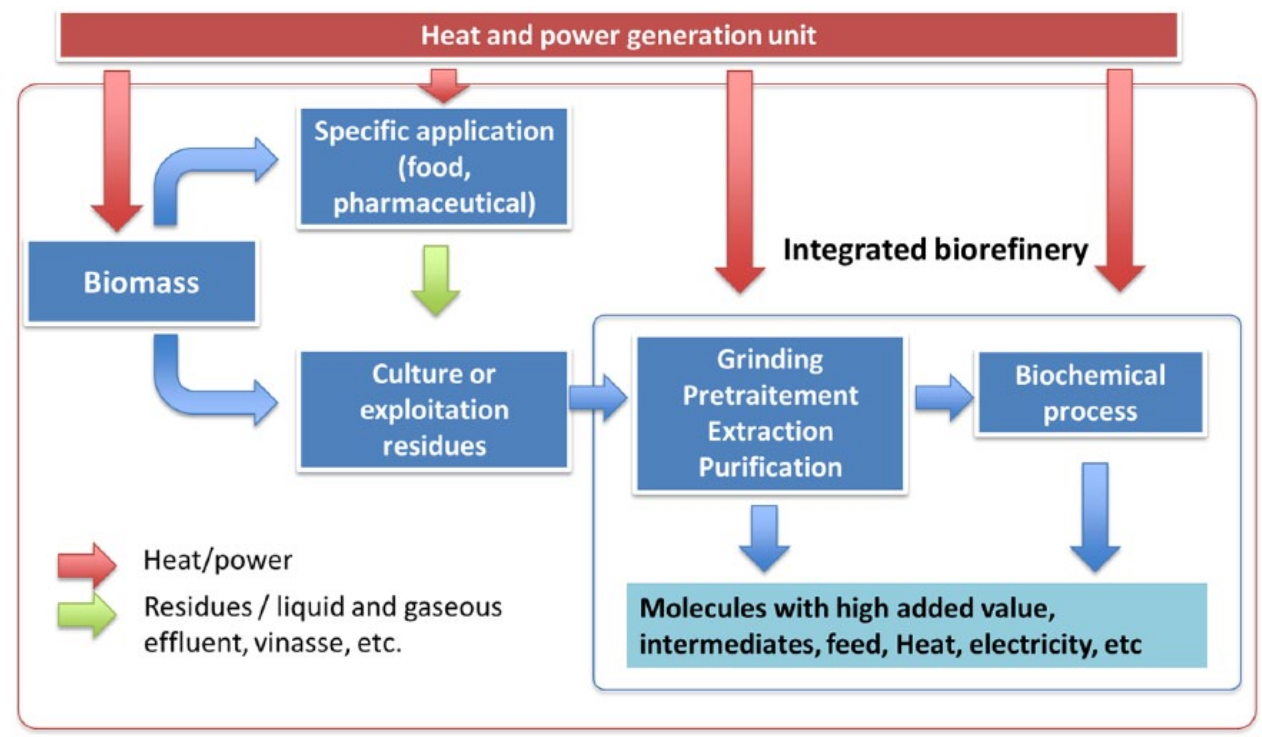

Figure 2. Integrated urban biorefinery benefiting of an energy external supply.

Without going so far in the deconstruction of the constituent of lignocellulosic biomass, opportunities are also emerging for several years. In the case of cellulose fibres, a series of chemical, enzymatic and mechanical treatments leads to the creation of nanofibres and nanocrystals with special properties (Dufresne, 2012). These properties, as well as the renewable and biodegradable nature of nanocellulose, enable it to potentially affect a huge variety of business, ranging from cosmetics, paints and textiles to electronics (Shatkin et al., 2014).

Beyond the traditional components of the biomass composed of sugars (cellulose and hemicellulose), lignin has a completely different structure. Lignin is an aromatic polymer compound of monolignols: p-coumaryl, coniferyl and sinapyl alcohol. The valuation of this bioresource is relatively interesting because lignin is the second component represented in the biomass after cellulose. Unfortunately, it has long been used as a fuel owing to its high calorific value (Voitkevich et al., 2012). Future research will help develop leads for the valuation of lignin. Lignin can be used in particular for the production of phenolic resins (Effendi et al., 2008), methanol, acetic acid, formic acid, acetaldehyde, methyl acetate, propanal, 1- hydroxybutanone, 2-butenal, furan, phenol derivatives, aromatic compounds (De Wild et al., 2009; Wang et al., 2007) and various hydrocarbons by synthesis gas production and Fischer-Tropsch synthesis.

\section{Conclusion}

In recent years, many efforts have been made in Belgium to carry the biorefinery of lignocellulose materials to the industrial level. However, efforts are still required. In the coming years, the 
depletion of oil reserves and global population growth will result in an increase in demand for biofuels and bio-based products. The second-generation biorefinery will therefore become a necessity.

In this context, this article shows that urban biorefineries, located in an urban or sub-urban areas implanted near waste treatment facilities and lignocellulosic residues production, could meet this demand. Two configurations are possible for theses biorefinery. Autonomous urban biorefineries that operate with residues, and gaseous and liquid effluent to produce their own energy. Integrated urban biorefineries that benefit from an energy supply from a nearby industrial activity.

These types of urban biorefineries also provide solutions to the Walloon context by promoting niche markets, especially those related to bio-based products and molecules with high added value, developing a circular economy model by the use of negative economic feedstock, avoiding the transport of supply feedstock and contributing significantly to the sustainable development.

\section{Declaration of conflicting interests}

The author(s) declared no potential conflicts of interest with respect to the research, authorship, and/or publication of this article.

\section{Funding}

The author(s) received no financial support for the research, authorship, and/or publication of this article.

\section{References}

Audsley E and Annetts E (2003) Modelling the value of a rural biorefinery - Part I: The model description. Agricultural Systems 76: 39-59.

Balat M (2011) Production of bioethanol from lignocellulosic materials via the biochemical pathway: A review. Energy Conversion and Management 52: $858-875$.

Bozell JJ and Petersen GR (2010) Technology development for the production of biobased products from biorefinery carbohydrates - the US Department of Energy's “Top 10” revisited. Green Chemistry 12: 539-554.

Carvalheiro F, Duarte LC and Gírio FM (2008) Hemicellulose biorefineries: A review on biomass pretreatments. Journal of Scientific and Industrial Research 67: 849-864.

Chintala R, Wimberly M, Djira G, et al. (2013) Interannual variability of crop residue potential in the North Central region of the United States. Biomass and Bioenergy 49: 231-238.

Chintala R, Djira G, Devkota M, et al. (2014) Modeling the effect of temperature and precipitation on crop residue potential for the North Central Region of the United States. Agricultural Research 3: 393-404.

De Wild PJ, Den Uila H, Reitha JH, et al. (2009) Biomass valorisation by staged degasification: A new pyrolysis-based thermochemical conversion option to produce value-added chemicals from lignocellulosic biomass. Journal of Analytical and Applied Pyrolysis 85: 124-133.

Demirbas MF (2012) Biodiesel from anchovy oil with supercritical methanol transesterification. Energy Education Science and Technology Part A: Energy Science and Research 29: 433-434.

Dufresne A (2012) Nanocellulose, From Nature to High Performance Tailored Materials. Berlin: de Gruyter.

Effendi A, Gerhauser H and Bridgwater AV (2008) Production of renewable phenolic resins by thermochemical conversion of biomass: A review. Renewable \& Sustainable Energy Reviews 12: 2092-2116.

Eggert H and Greaker M (2014) Promoting second generation biofuels: Does the first generation pave the road? Energies 7: 4430-4445.

Eisentraut A (2010) Sustainable production of second generation biofuels, potential and perspectives in major economies and developing countries: Information paper. International Energy Agency: 02/2010.

Gavrilescu M (2014) Biorefinery systems: An overview. Bioenergy Research: Advances and Applications, chapter 14, pp. 219-241.

Kamm B (2007) Production of platform chemicals and synthesis gas from biomass. Angewandte Chemie International Edition 46: 5056-5058.

Kokossis AC (2014) Design of integrated biorefineries. Computer Aided Chemical Engineering 34: 173-185.

Kokossis AC and Yang A (2010) On the use of systems technologies and a systematic approach for the synthesis and the design of future biorefineries. Computers and Chemical Engineering 34: 1397-1405.

Kumar P, Barrett DM, Delwiche MJ, et al. (2009) Methods for pretreatment of lignocellulosic biomass for efficient hydrolysis and biofuel production. Industrial \& Engineering Chemistry Research 48: 3713-3729.

Jacquet N, Desquay L, Jadot B, et al. (2015) Les initiatives commerciales de bioraffinage en Région Wallonne: production de biocarburants et voies de valorisation connexes. Biotechnology, Agronomy and Society and Environment 19: 197-203.

Laurent P, Roiz J, Wertz JL, et al. (2011) Le bioraffinage, une alternative prometteuse à la pétrochimie. Biotechnology, Agronomy and Society and Environment 15: 597-610.

Shatkin JA, Wegner TH, Bilek EM, et al. (2014) Market projections of cellulose nanomaterial-enabled products - Part 1: Applications. Tappi Journal 13: 9-16.

Sheldon-Coulson GA (2007) Production of levulinic acid in urban biorefineries. Thesis, Massachussets Institude of Technology.

Stuart PR and El-Halwagi MM (2012) Intergrated Biorefineries: Design, Analysis and Optimization. CRC Press.

Talebnia F, Karakashev D and Angelidaki I (2010) Production of bioethanol from wheat straw: An overview on pretreatment, hydrolysis and fermentation. Bioresource Technology 101: 4744-4753.

Voitkevich O, Kabo G, Blokhin A, et al. (2012) Thermodynamic properties of plant biomass components. Heat capacity, combustion energy, and gasification equilibria of lignin. Journal of Chemical an Engineering Data 57: 1903-1909.

Wang Z, Lin W, Song W, et al. (2007) Bio-fuel and chemicals by thermochemical treating of biomass. Progress in Chemistry 19: 11901197.

Wiloso EI, Heijungs R and De Snoo GR (2012) LCA of second generation bioethanol: A review and some issues to be resolved for good LCA practice. Renewable \& Sustainable Energy Reviews 16: 5295-5308. 